A most significant feature in this circumstantial account is that it tallies to some extent with the narrative given by the officers of H.M.S. Daedalus of the appearance of the sea-serpent seen by them in the year 1848 in the Atlantic.

In the figures given by Oudemans the (double) back-fin is very low, and the neck seems relatively short and ill-defined. Revised restorations, however, give a longer neck and no back-fin. It is possible, if a fin was present, that its apparent difference in height in the two instances was due to the animal swimming faster in one case than the other. Megophias megophias, it appears, is a name which has been suggested for the creature. In I903 Prof. Racovitza (Bull. Soc. Zool. Paris, xxviii., p. II) gave an account of a sea-serpent seen by Lieut. Lagresille in $I 898$ in Along Bay, Tonkin, and in 1904 M. Vaillant (Bull. Mus. Paris, x., p. 217) mentioned another apparition of an apparently similar creature in the same locality. In this second account the animal is described as being probably scaled, with a head like that of a turtle or a seal, and as "spouting" from terminally placed nostrils. It was also stated to move in undulations - at one time vertical, at another horizontal. Two occurrences in the same locality are very noteworthy.

In each of these four instances it can scarcely be doubted that the object seen was a living creature (or creatures) of some kind, and that it (or they) was of the same general type. If the object were formed by more than one animal, cadit quaestio. If, on the other hand, it consisted of a single individual, furnished with a dorsal fin, a long, snake-like neck, and a head like a turtle, it could scarcely be any known living animal. Neither, it may be suggested, could it be even an unknown type of seal, especially since all the known members of that group come ashore to breed. The next question is, Could it have been a survivor of some Mesozoic reptilian? Two arguments, so far as they go, are against this. Firstly, the one referred to by $\mathrm{Mr}$. True as to the absence of the remains of any such creature in Tertiary deposits, and secondly (on the hypothesis that it is an air-breathing vertebrate, and if not, why should it come to the surface at all?), the rarity of the seaserpent's appearance, the latter argument being applicable whether the creature is considered to belong to a supposed extinct group or not.

With regard to the fossil theory, it might be urged that the creature is an inhabitant of the deep sea, and consequently that its remains should not be expected to occur in Tertiary deposits, which belong for the most part, at any rate, to more or less shallow water. For what it is worth, it may be mentioned in reply that no traces of the creature have been found on the ocean bottom, where sharks' teeth and cetacean ear-bones are common. A more forcible objection is that, if the creature is in the habit of coming to the surface (as on the hypothesis of its existence it must), it cannot be a denizen of the abysses, no animal (despite the old belief in regard to whales) being able to live under such diversities of pressure. Ergo, its remains ought to occur in Tertiary deposits. Its stranded carcase ought also to have been found. If the creature be a "living fossil," the plesiosaurian group has the strongest claim to its ownership, as, although the zeuglodont cetaceans are the latest in time of possible extinct representatives, the smallness of its head prevents the reference of the sea-serpent (as described) to that group. As to the rarity of its appearance, it can scarcely be urged that only two or three (or even half a dozen) examples of the creature are in existence.

NO. I 9 I 3 , VOL. 74]
Without offering any suggestion as to what the nature of the object seen by Messrs. Nicoll and MeadeWaldo really was, it may be pointed out that the testimony of two such trained observers (supplemented by that of the officers of the Daedalus and by the two "apparitions " off Tonkin) cannot possibly be brushed aside in the light-hearted manner with which Prof. Moseley treated the evidence available in his time.

R. L.

\section{THE ROYAL SOCIETY CONVERSAZIONE.}

MANY of the exhibits of scientific apparatus and objects at the second, or ladies', conversazione held at the Royal Society on June 20 were the same as those shown at the gentlemen's conversazione on May 9. As these have already been described (May I7, p. 59); it is only necessary to refer now to the new exhibits. During the evening demonstrations, with lantern illustrations, were given by $\mathrm{Dr}$. Tempest Anderson, Sir William Crookes, and Mr. Fred. Enock. Dr. Tempest Anderson described the recent eruption of Vesuvius, his photographs showing the phenomena during the later stages of the eruption, as well as some of the results. In several cases the views afforded a comparison with the conditions of the same places as previously observed. Sir William Crookes gave a short address with experiments in illustration of some properties of the diamond; and Mr. Fred. Enock described slides showing by means of colour photography (Sanger Shepherd process) the adaptability of lepidopterous insects to their environment.

In the subjoined summary of the official catalogue, the exhibits are arranged roughly in groups of related subjects.

Dr. H. Forster Morley on behalf of the International Catalogue Committee: A map of the world was shown upon which thirty-one countries or regions were coloured. Each of these has established a Regional Bureau for indexing its scientific literature. The literature indexed is that published since January I, I9or. Each annual issue of the catalogue contains seventeen volumes, dealing with seventeen sciences. A copy of the second annual issue was shown. The Regional Bureaus for France, Germany, and that for Polish literature employ the material prepared for the International Catalogue for the compilation of bibliographies of their own scientific literature. Specimens of these bibliographies were shown.-Prof. H. McLeod on behalf of the Committee of the Royal Society's Catalogue of Scientific Papers: An exhibit illustrating the course of operations in the preparation of the catalogue, which was fully described in an appendix to the descriptive programme of the conversazione.

Sir James Dewar, F.R.S.: (I) New charcoal calorimeter and thermoscope. Charcoal at the temperature of liquid hydrogen that has absorbed at atmospheric pressure considerable quantities of helium or hydrogen-or alternatively of nitrogen, oxygen, or air at their respective boiling points -is utilised in this instrument as a material that, by reason of changes in the volume of the occluded gas, exhibits great sensibility to heat and light radiation, and can be used in calorimetry at the temperature of solid hydrogen. (2) Charcoal vacua. Electric discharge tubes showing gradual gas absorption by charcoal cooled in liquid air until, after the Röntgen radiation stage, the electric resistance becomes so great that a discharge will not pass. (3) Spectrum tubes. (a) The less condensable gases of the atmosphere-helium and neon. (b) The more condensable gases of the atmosphere-krypton and xenon, each set of gases being separated by the charcoal method. (4) Some scientific uses of liquid air. (a) Electric ice crystals. (b) Rough measures of relative thermal conductivities in metals and alloys, by observing the height of the deposited ice cap when similar wires are placed alongside each other 
and the ends immersed in liquid air. The relative conductivities are as the squares of the height of the ice columns. (c) Spheroidal state of liquid air on the surface of different fluids and solutions, showing changes of volatility from the varying amount of vapour condensation; at the same time exhibiting interesting rotatory and translatory movements.-Department of Applied Mathematics, University College, London: (I) Investigation into the stresses in masonry dams, Prof. Karl Pearson, F.R.S., and Mr. A. F. C. Pollard. The investigation suggested that the shear distribution should in each case be found from a model dam, before the stresses are determined by graphical methods. The existence of stretch in the tail of dams of ordinary type is confirmed by the experiments illustrated. (2) Solution of the problem of the random walk, Prof. Karl Pearson, F.R.S., and Mr. J. Blakeman. The diagrams shown give the sections of the frequency surface for two, three, four, five, six, and seven stretches or flights, and show the passage of the discontinuous function into Lord Rayleigh's continuous surface. The problem is of considerable importance from the standpoint of the migration of species, and was suggested by Major Ross's investigations into the infiltration of mosquitoes into a cleared district. The solution has been obtained by successive mechanical integration from the first case by using the functional relation between successive flights.- $M r$. A. A. C. Swinton: Visibly luminous electrical discharges in vacuo obtained with comparatively low electrical pressures. Edison, Fleming, and others have shown that the passage of the electric discharge in vacuo is much facilitated by heating the kathode. Owen and Wehnelt have proved that this effect is enormously increased if the heated kathode be coated with oxides of the alkaline metals. The present experiments show that similar results can be obtained by coating the kathode with radium, and that the effect will be greater when the kathode is heated than obtains without heating.-Mrs. Watts-Hughes and $M r$. Richard Kerr: Floral, geometric, and other forms produced by the human voice in singing. Moistened water-colour is spread on paper attached to an india-rubber disc stretched over a cup-shaped vessel. The sound vibrations are communicated to the under side of the india-rubber through a tube in the side of the cup.-Mr. Oliver S. Dawson: Photographic prints in natural colours (Smith-Merckens process).-Messrs. Carl Zeiss, Jena: Photomicrographic apparatus for ultra-violet light (designed by Dr. A. Köhler).

$M r . R$. G. Durrant: Evidence to show that ionic separation occurs when solutions of acids or of salts are allowed to diffuse into sensitised jellies or solutions.- $D r$. $O$. Silberrad and Dr. R. C. Farmer: Stability test for cordite. This exhibit illustrated a method recently devised at the Chemical Research Department, Royal Arsenal, Woolwich, for the determination of the stability of cordite and other propellant explosives. It is well known that these explosives decompose gradually on storage, and may eventually ignite spontaneously, if their stability be not tested from time to time. The principle of the new test is based upon the results of several thousand experiments, and is the only method known which gives trustworthy results with cordites. The test has been adopted by the Service, and will shortly be made use of as a safeguard against spontaneous explosions in powder magazines, particularly in the tropics, where the deterioration takes place most rapidly. In examining cordites the procedure is briefly as follows:-50 grams of the explosive are maintained at $70^{\circ} \mathrm{C}$. in a glass vessel fitted with a mercury manometer; the alteration in pressure is measured at intervals. A contraction takes place at first owing to the absorption of oxygen from the air ; subsequently a gradual expansion occurs; the former of these phenomena has never previously been observed.-Dr.F. D. Chattaway: Copper mirrors obtained by the deposition of metallic copper upon glass. The method of silvering glass by depositing the metal in a thin film by reduction of some soluble silver compound has long been employed in the production of mirrors, but hitherto no method of similarly depositing copper in a brilliant film has been discovered. The exhibit showed a number of glass vessels on which copper had been thus deposited by a slow reduction of the black No. I 9 I 3 , voL. 74 ] oxide. The metal being protected from the air, such mirrors retain their lustre permanently.

Mr. G. F. Herbert Smith: Precious stones and simple methods for their identification. This exhibit illustrated the variety of precious stones which are available for ornamental purposes. A gem stone must be hard enough to resist the abrasive action of ordinary dust, and at the same time be either transparent or, if opaque, of pleasing colour. The number of mineral species suitable for the purpose is not so restricted as popularly supposed: The names employed by jewellers frequently differ considerably from the scientific nomenclature, being often associated with certain colours rather than particular species, e.g. topaz (yellow), sapphire (blue), ruby (red), emerald (green), and amethyst (violet). The colour, though the most obvious character of a stone, is the least trustworthy; and the hardness, while of immense importance as regards its durability, is of little discriminative value. On the other hand, the optical characters (refractivity, double refraction, and dichroism) and the specific gravity may be easily and accurately determined, and lead to the precise identification of the stone. In the case of practically all faceted transparent stones the refractivity and double refraction are sufficient for the purpose, and the stone need not be removed from its setting.-Sir William Crookes, F.R.S.: (I) Occurrence of the diamond. (a) Example of "blue ground " in which diamonds are found, from the 1320 -feet level, De Beers Mine; (b) diamantiferous gravel from the Pulsator, De Beers Mine; (c) selected stones from the Pulsator, De Beers Mine. (2) Models of crystals of diamond. (3) Cut and polished section of a piece of silicified wood found about twelve years ago in the untouched "blue ground" of the Du Toits Pan Diamond Mine, Kimberley. (4) Polished section of the Cañon Diablo meteorite in which diamonds have been found.-Prof. $W$. Gowland: ( $\mathrm{r}$ ) Portion of a meteorite containing diamonds found near Cañon Diablo, Arizona, and specimens of diamonds extracted from it. (2) Alloys of copper and calcium. A series of alloys ranging from 0.8 per cent. to $6 \mathrm{I} \cdot 5$ per cent. of calcium. All are brittle, and those containing 6 per cent. to 7 per cent. calcium extremely hard. The higher alloys decompose water, and are readily oxidised in the air. Specimens were also exhibited showing the effects of calcium on lead, tin, bismuth, aluminium, and coinage bronze.-Miss Rhodes: Stereoscopic views of the Victoria Falls and the Batoka Gorge of the Zambezi, and of the Batoka country east of the Falls. Photographed by the late Colonel F. W. Rhodes.

The Director, Royal Gardens, Kew: Sturt's desert pea (Clianthus Dampicri). A prostrate herbaceous plant, native of West Australia, first collected by Captain William Dampier. Under cultivation it is very delicate, but when grafted on the bladder senna (Colutea arborescens) it grows with vigour and flowers freely.-Dr. F. E. Fritsch: Method of colonisation of free surfaces by subaërial Algre (Cyanophyceæ) in the tropics.-Mr. E. A. Newell Arber, Miss M. Benson, Miss $W$. Brenchley, Prof. $F$. W. Oliver, F.R.S., Dr, D. H. Scott, F.R.S., and Prof, F. E. Weiss: Fossil plants from the English Coal-measures.-Mr. W Saville-Kent: Stereoscopic and other natural-colour photographic transparencies illustrating the fauna of the Polynesian coral reefs. This series of natural-colour photographs was more particularly illustrative of the coralfrequenting fishes of Polynesia. A notable genus of mostly minute percoid fishes, Tetradachnum, represented in the series, habitually make isolated bushy coral stocks their headquarters. They cruise around these coral growths in sport and in search of food, retreating within the coral's ramifications to rest or to escape from any enemy.

The Solar Physics Observatory, South Kensington: Recent photographs of some British stone circles.-Dr. W. M. Flinders Petrie, F.R.S. : (1) Hyksos fortress model and pottery, 2000 B.c., Egypt. (2) Model of the temple and city of Onias, Egypt. (3) Photographs, enlarged, from Sinai. The Esyptian turquoise mines were worked from 5000 B.c. The oldest rock sculptures are those of the middle of the first dynasty of kings. Both centres of mining, Wady Maghara and Serabit el Khadem, were shown. 